\title{
Governmental Theories - Students' Responses: Student Strategies Reacting to Changes in Hungarian Higher Education
}

\author{
DOI: 10.12776/QIP.V21I3.921
}

\author{
Rita Csőke, Zsuzsanna Eszter Tóth
}

\begin{abstract}
Purpose: By analysing enrolment data for the past few years, this paper searches for the answer to what extent government interventions influence the choices of students entering to higher education.
\end{abstract}

Methodology/Approach: The paper analyses statistical data of higher education applications and admissions for the 2010-2016 interval.

Findings: The analyses presented in this paper strengthen the fact that a significant number of students is ready to undertake financial burdens (i.e. pay tuition fee) in order to achieve their own goals or to disclose government restrictions and obligations, surprisingly even in STEM (science, technology, engineering, mathematics sciences) education. Despite the governmental interventions, economic faculties are still the most popular ones, while the politically favoured STEM faculties have not become more favourable due to the state subsidies.

Research Limitation/implication: Quality management activities of higher education institutions should strongly focus on and reflect to potential students and their needs, since it is primarily the students' choice to enrol to a specific institution's specific faculty, and if yes, to which.

Originality/Value of paper: According to the best of our knowledge this is the first analysis which has incorporated enrolment limit scores in the process of evaluation. Compared to the descriptive analyses available in Hungary, our research results have resulted in a more complex conclusion on the same basis.

Category: Research paper

Keywords: higher education; enrolment; student preferences 


\section{INTRODUCTION}

A key question of quality management in higher education (HE) or in a particular higher education institution (HEI) is the identification of the 'customer'. Who is the one for whom a HEI provides a service, and whose expectations should primarily be met when it comes to quality issues? Is it the state or the students who 'buy' higher education services? Whose expectations would and should predominantly influence quality-related decisions and measures made by HEIs?

It is now evident that the direct customers of $\mathrm{HE}$ are the existing and potential students. However, the major role of state through various means of state funding cannot be neglected. The state also influences the existence and operation of HEIs, both directly and indirectly. In Hungary, an evident mean to intervene into $\mathrm{HE}$ is the distribution of state-financed student places for newly entering students among institutions and fields of studies. The state seems to enforce its preferences partly through these measures, namely, in terms of the number of state-funded degrees. Through this process the state validates its own criteria and intends to directly influence the number of students on particular fields of study at the institutions. Moreover, by doing so, the state directly influences the funding of an institution or a faculty. As a natural consequence, there should be a competition between institutions for state-funded students, as well as for attracting as many fee-paying students as they can. After all, students make a decision between faculties and institutions.

$\mathrm{HE}$ and the knowledge and skills acquired during these studies serve to achieve individual life goals. Another considerable characteristic of a 'high quality' HE system is its major contribution to the improvement of macro economy. By now, direct and indirect economic impacts of HE have almost become stereotypical both abroad and in Hungary. The positive socio-economic effects of $\mathrm{HE}$ are also supported by Hungarian official statistical data. Data from the Hungarian Central Statistical Office and the National Employment Service (KSH, 2017 and NFSZ, 2017) also confirm that HE graduates have higher salaries and a lower chance of unemployment than those with lower qualifications (e.g., Green, 1994; Dennison, 1989; Woodhall, 2007).

In 2011, the Hungarian government announced a significant intervention in the Hungarian HE policy. The Hungarian Parliament adopted the Act on National Higher Education in 2011, which entered into force in 2012. According to the Act, the condition of (partial) state grant is that the student shall be obliged, 'within twenty years after acquisition of the degree, to enter into and maintain employment or other work related status resulting in social insurance with an employer under Hungarian jurisdiction or undertake entrepreneurship under Hungarian jurisdiction (hereinafter: Hungarian employment) for a duration twice the length of the period during which he/she received (partial) state grant, an obligation which may be met in several stages. Meanwhile, the government drastically reduced the state-funded capacity of law, economics and humanities programmes. Meanwhile, the student loan system for financing tuition fees has 
also undergone a major development. The government also announced its primary focus on technology, IT and natural sciences programmes. Furthermore, at governmental level a priority was set up between university degrees and vocational training, by expressing that 'the honour of manual labour has to be restored'.

As of the aim of our paper, this legal-political change has offered a unique opportunity to examine the effects of governmental policies on students, how they react to such changes which clearly have effect on their future. The paper seeks the answer to how and to what extent state measures related to $\mathrm{HE}$ influence the decisions of potential students, and whether individual preferences change, and if yes, how, if the state changes the conditions and its preferences. Since no significant demographic change or other relevant large-scale event have taken place in the examined time period, it may be assumed that the sudden drastic changes relate to the political and legal interventions concerning $\mathrm{HE}$ in Hungary.

\section{METHODOLOGY}

Hungarian official HE database was examined for years 2010-2016 (available publicly at www.felvi.hu, the official website of the Hungarian Educational Authority). Amongst the data, the followings have been chosen for further investigation: first-place applications by fields of studies and by age groups; admission data by fields of studies and by financing forms; and the minimum (average) entering scores by fields of studies.

First-place applications show the primary aspiration of an applicant. According to the Hungarian HE application system, one can appoint several programmes of even different fields of studies expressing a preference ranking. That is the reason why all application data are not appropriate for our purpose, since the mere numbers of how many courses are listed altogether by all applicants do not say anything about either the number of the applicants (since one may choose several programmes) or their real preferences. The actual number of people behind the total applications can be best observed through first-place applications.

The admission data by fields of studies, and by financing forms have also been found expressive. These data can also indicate much about future students' attitude. Since applicants' preference lists include not only specific programmes at given fields of studies, but they also have to add the financing forms (statefunded or fee-paying or both with a ranking) they are applying for, the application data from this aspect is also a meaningful factor. Since the government's most impressive mean to directly influence the structure of HE is the allocation of state-financed places, the changes in the admitted students' financing forms are strong indicators of students' motivation. If state financing is not available for a student (either due to entering results, or to the lack of 
sufficient available state-financing at a given programme), are they willing to pay tuition fee for their studies just to follow their own goals, or do they change their preferences and study what is available 'for free'?

Thirdly, the minimum entering scores and the changes in their averages by fields of studies at different levels and financing forms are examined. Through minimum entering scores the number and also the quality of students can be governed. The common assumption is that the higher the minimum entering score is, the fewer students can achieve that, but they are of better quality. By analysing the minimum entering scores, the following expectations may be formed. Where the number of applications decreases, in order to compensate this loss, HEIs would lower their entering score limits, especially at those studies and for those students where state-financing is not available or fee-paying of students is more dominant. Where the state explicitly supports a given field of study, in order to attract potential students and to fill in the state-financed places, HEIs would also reduce the entering scores.

But has this really happened? A number of changes, including considerably varying faculty structures and programmes have taken place in Hungarian HEIs during the examined period. Some programmes have newly been launched and some programmes have not been continued. Some fields of studies were statistically merged into others (like social services fusion with social sciences field of study) and some data inaccuracies can also be observed as well. For this reason, an all-encompassing and completely accurate data collection and analysis were not the main goal. It is also important to note that the used official www.felvi.hu statistics do not contain the data of postgraduate specialist training courses, and where separable, we have not considered HE courses that do not offer a degree.

\section{RESEARCH RESULTS}

\subsection{An Overview of the Hungarian Higher Education in a Wider Perspective}

The 16-year long data show two significant waves both with its own peaks and bottoms (Figure 1). The first major fluctuation took place between 2004-2009. This period clearly shows how the Hungarian society and potential students learnt to adopt the Bologna process. The process reached its deepest point in 2007, after which the numbers started to increase again. By 2010, the number of $\mathrm{HE}$ applicants and admissions was close to the numbers of 2004 and continued to slightly rise until arriving at a peak in 2011.

Hungarian HE experienced a second 'nosedive' within the examined period. Unlike the previously described period, the trough of this wave (examined to 2016) following the high point of 2011 shows a different curve. The number of those applying for higher education dropped down to the previous low point in 
only a two years time, and the curve of the following ascent takes a different shape as well. Even in the 6th year of the trough of this wave no data indicate that there might be a return back to the previous level of 2011. The number of applications has slightly increased since 2014, though still nearly a quarter of the applications has disappeared by 2016 compared to 2011. As of the figures of the admitted students, the same tendency is visible. Besides a modest increasing trend of applications, the number of admissions seems to get stabilized close to the minimum of this second circle. This is hardly higher than the deepest point of the 16-year long period, namely, the same data of 2007. It is also worth mentioning that the proportion of the state-financed students is somewhat higher in the all admitted, though their allocation has changed significantly.

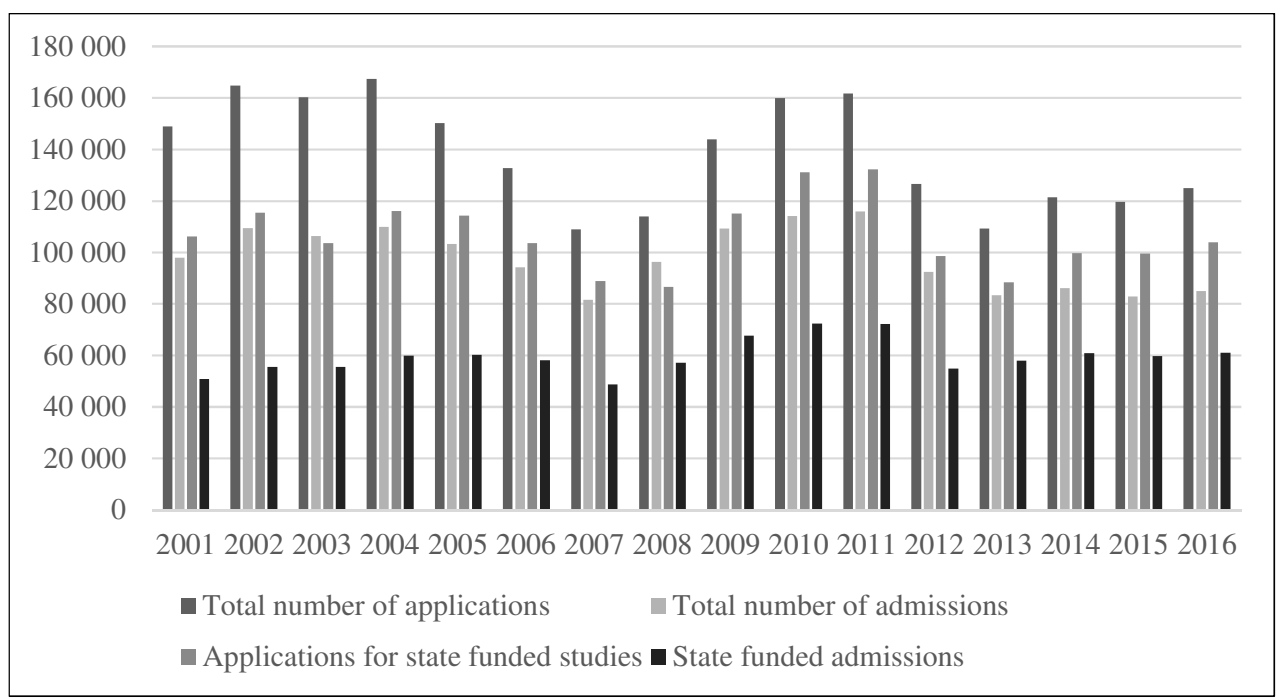

Figure 1 - Distribution of Applications and Admission in Hungary (2001-2016)

So remarkable change(s) took place from 2011 to 2012 that HE lost more than $20 \%$ of applicants from one year to the other and an additional more than $10 \%$ by 2013. From 2011 to 2012 more than 35,000 fewer students applied for Hungarian HE programmes taking only first-place applications into account. The deepest point of the second wave was in 2013, and the 'upswing' in the number of applications and admissions means only that in 2016 the number reached a value that barely surpassed the lowest level of the longer (2001-2016) period. The number of admissions was only $4 \%$ higher than the all-over minimum of a 16 year cycle in 2007 .

\subsection{Analysis of First-Place Application Data According to Fields of Study (2010-2016)}

If we examine the first-place applications according to their distribution among the fields of study, an 'inverted J- shaped' curve appears in the majority of cases in terms of total applications during the same period of time. 
Fig. 2 clearly shows that there are only three fields of study where the number of first-place applicants in 2016 is higher or about the same as the corresponding number of 2010. The field of public administration, police and military trainings (where a typical 'inverted U- shaped' curve can be identified indicating a decreasing trend); the pedagogic programmes, where after hitting a bottom in 2012, the number of applications has grown in a way that they have exceeded the high values of 2010; as for medical training and health sciences programmes, the curve resembles a 'flat U- shape'. During this period, a slight decrease can also be recognised in the number of applicants, but not as much as in the case of other fields. By the end of the period, the number of applications essentially returned to that of the beginning, even if not to the peak.

Fig. 2 explicitly illustrates that the changes affected almost every fields of study to different extents. A general loss of applicants in the whole sector can also be observed in the examined period, though, some fields of study were more affected by this phenomenon than others.

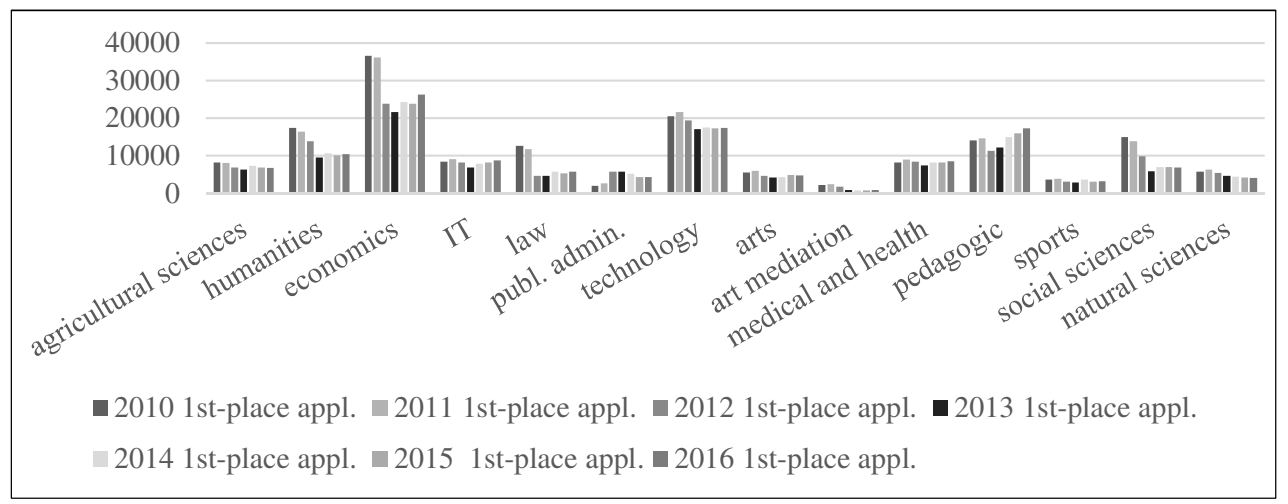

Figure 2 - Changes in First-place Applications According to Fields of Study (2010-2016)

Upon the average numbers of first-place applications, the following 'popularity list' can be set up: (1) economics programmes, (2) technology programmes, (3) pedagogic programmes, (4) humanities programmes, (5) social sciences programmes. These fields have produced first-place application averages above the all-over average of 9,426 for all the fields of study within 2010-2016 (the only exception is the field of social sciences, where social services studies merged into this field in 2013. Without counting with social services, the firstplace applications to the studies in social sciences would also enhance the allover average).

To have a quick impression on where we started and where we currently are, the simplest way is to grab the change in the numbers of first-place applications as a simple difference between the applications in the initial year (2010) and the final year (2016) of the analysed period. Using this method, the difference is 35,052 potential students, that is $22 \%$ of first-place applicants of 2010 , which is a huge 
number. As no apparent demographic reasons can be identified during this period, it can be stated that in 2016 every fifth applicant has not even tried to enter the Hungarian HE system compared to 2010.

If the differences between the numbers of first-place applications from 2010 to 2016 are also examined, it can also be seen that except for pedagogic programmes the most favoured ones (and law programmes in addition) suffered the biggest losses.

Fig. 3 depicts that by 2016 five fields of study had to endure an over-average loss of applicants. For the most part, these fields are identical to those of the aforementioned 'top list': economics programmes are clearly 'leading', where the loss of first-place applications from 2010 to 2016 was more than 4 times above the average, followed by social sciences, humanities, law and technology programmes. Thus it can be concluded that the most popular fields of study with the highest number of first-place applications and law programmes 'took a far bigger share' in the decrease as of the numbers of applicants. There was a slight $(4 \%)$ increase in the number of first-place applicants in information technology programmes between the beginning and the end of the period. After the general low point of 2012-2013 (which affected the information technology field the least as of absolute numbers) this field of study was able to retrieve the number of its applicants and produced a slight increase.

There were only two fields that experienced a significant increase in applications: pedagogic programmes and the fields of public administration, police and military training (however, it is important to remember the fact that this particular field shows a 'reverse U-curve' instead of the typical 'reverse J' one. First the number of applicants increased, then decreased in the designated period, thus not having been able to hold on to the increasing inclination to apply at the beginning and middle of the period).

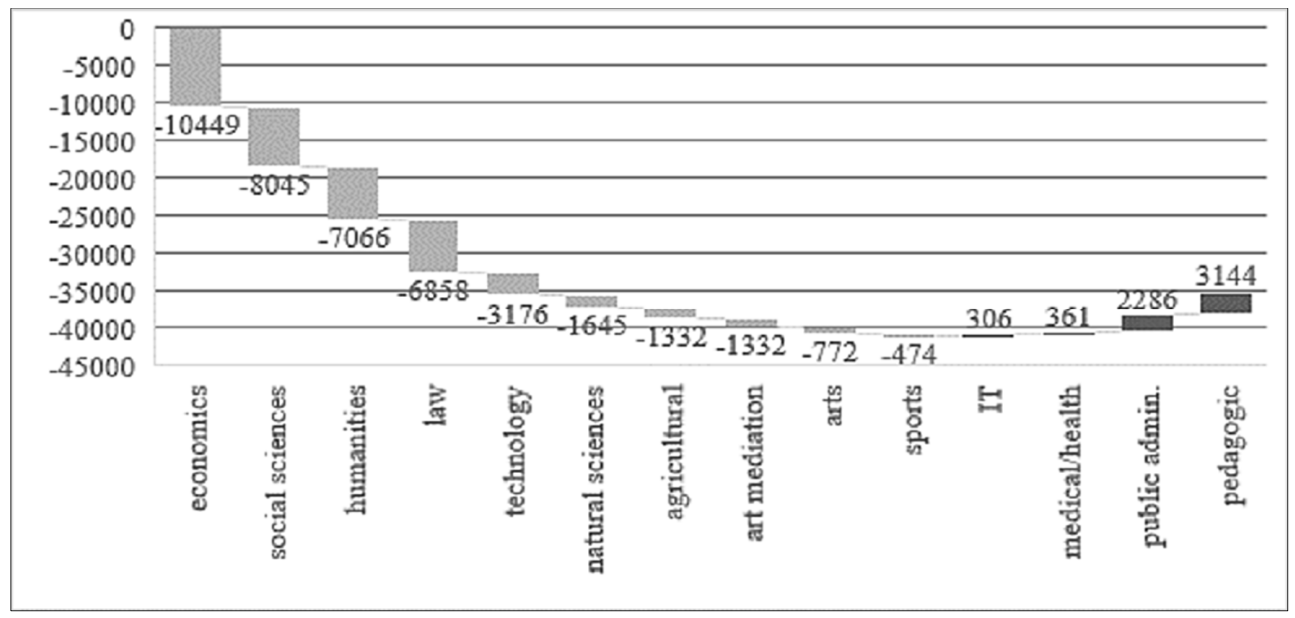

Figure 3 -Differences in the Numbers of First-Place Applications between According to Fields of Study (2010-2016) 


\subsection{Analysis of Admission Data According to Fields of Study Between 2010-2016}

After analysing applications, the data of students admitted into HE are examined.

\section{Analysis of All Admitted Students (2010-2016)}

As expected, Fig. 4 demonstrates that the curves that are characteristic of those applying for HE look very similar to those of the students who were finally admitted. Compared to 2010, the number of admissions was approximately 29,000 less in terms of student numbers in 2016.

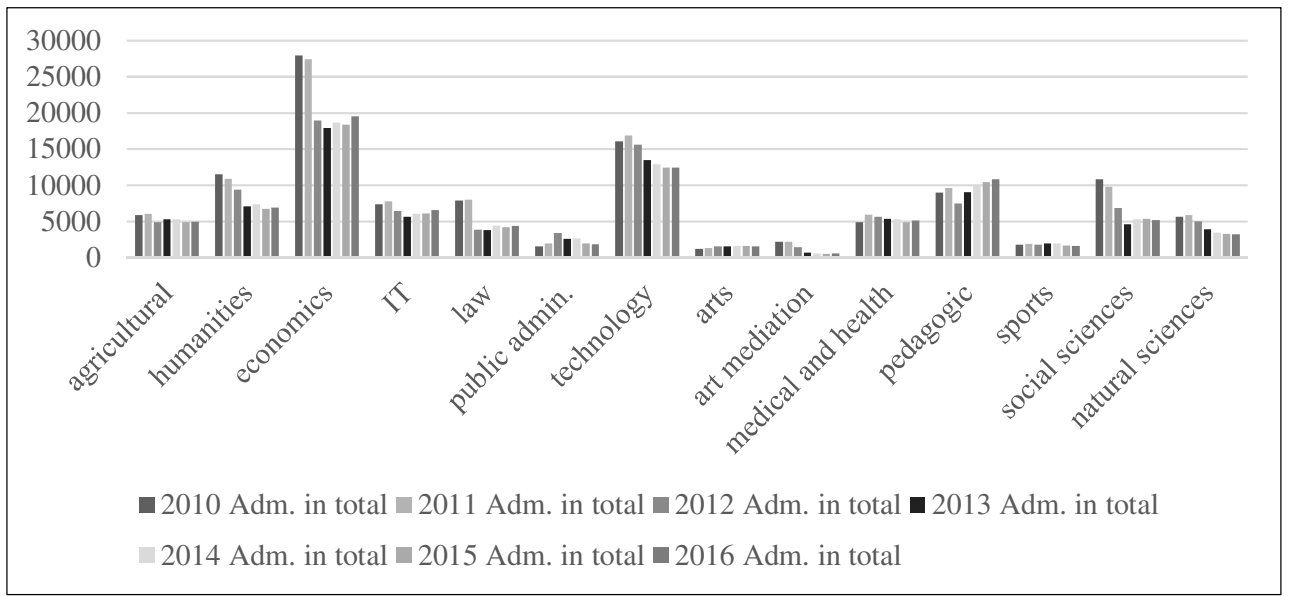

Figure 4 - Number of Admitted Students According to the Fields of Study (2010-2016)

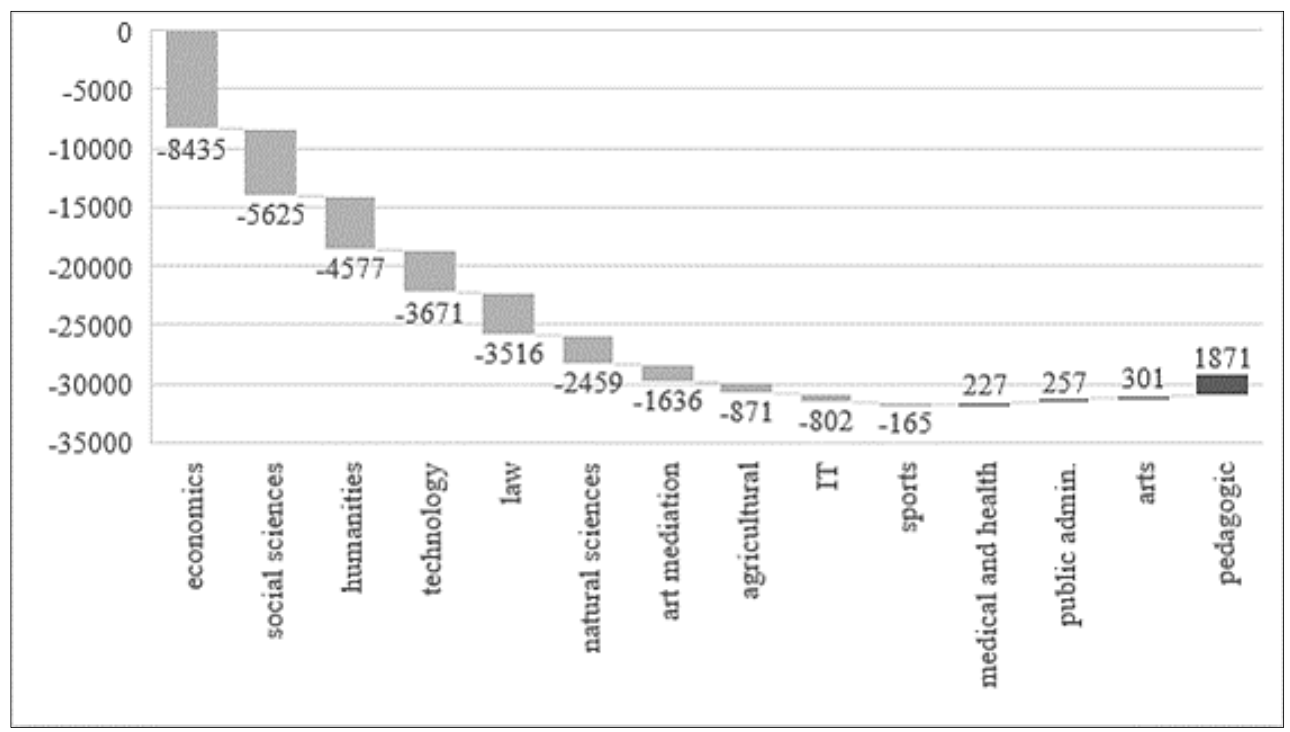

Figure 5 - Difference in the Number of Admitted Students by Fields of Study (2010-2016) 
There is a 'top list' that is identical to the one based on the analysis of first-place applications by examining the average number of admissions in the period of 2010-2016. Not surprisingly, the admission numbers of the most popular fields dropped back most considerably, though in a bit different order. So the 'top list' of those losing the most students is almost the same as of applications, with law 'coming up' and without pedagogic programmes, which eventually increased (Fig. 5).

When comparing the differences of first-place applications and admissions, Figure 6 shows that the cut in the number of applications was normally followed by a decrease in admissions by a lower extent. While the drop of first place applications was 35,052 students, the fall in the number of total admissions is by 29,101 students less (17\%) from 2011 to 2016 . This seems reasonable, since the capacities of HEIs have not changed that much as the interest of the potential students. So it seems rational that among fewer applicants, institutions enrol as many students as reasonably possible. Despite all expectations, the number of admitted students to IT, technology, natural sciences and public administration fields decreased at a greater extent than the number of their first place applications (Fig. 6). Compared to 2010, by $10 \%$ fewer students were admitted even in the case of IT studies, meanwhile the number of first-place applications increased by $4 \%$ (we also have to mention that in 2016 there was a $7 \%$ increase in the number of admitted students to IT studies, compared to the previous year, otherwise the decline would be even more out of ordinary). Another unexpected trend can be caught at technology education. At this field there are also visibly fewer admissions than the decrease of applications. This seems really weird and is contrary to the general trends and policy intentions. A reasonable explanation to this phenomenon can be that institutions in technology education (in average) raised their quality requirements irrespectively of the decreasing student interest.

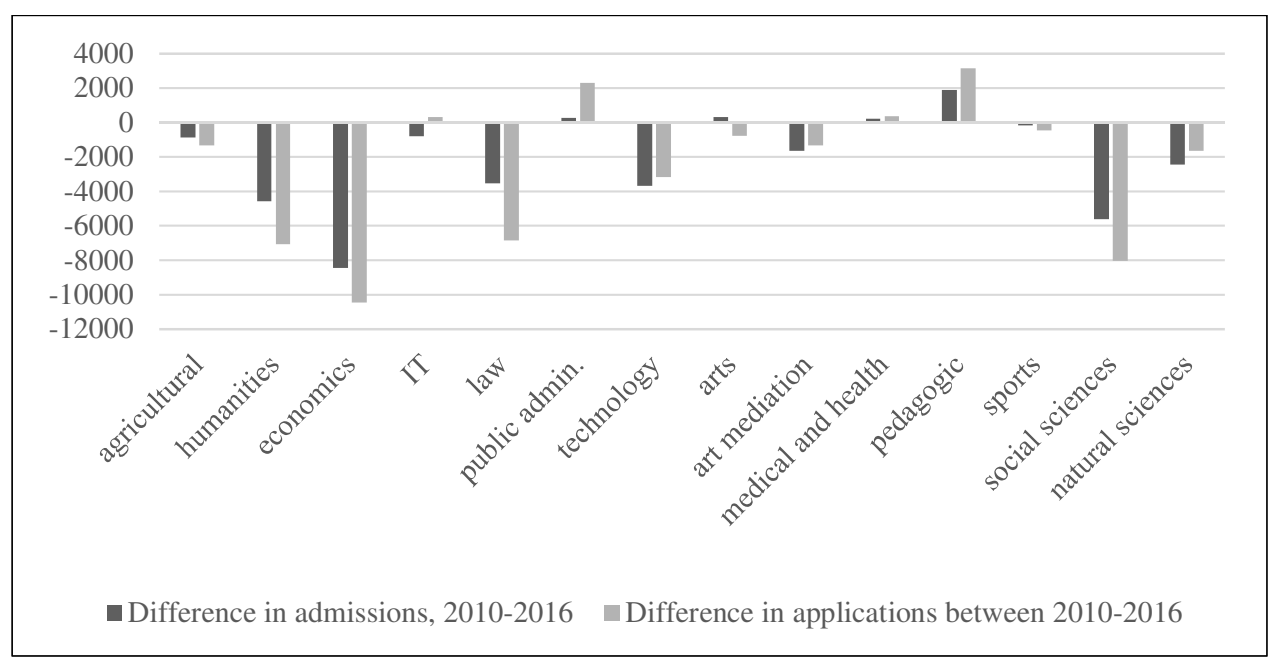

Figure 6 - Comparison of Differences in First Place Applications to Admissions (2010-2016) 
After examining the absolute numbers, where one can experience huge decreases, the changes of the proportions of admissions at the fields from 2010 to 2016 developed absolutely unexpectedly (Fig. 7). The biggest change can be observed in case of pedagogy showing a $4.9 \%$ increase, while the negative 'recorder' was the field of social sciences with a $3.4 \%$ decrease in its proportion of all admissions. All the other fields are in between $1.7 \%$ and $-1.9 \%$. These data do not show any significant rearrangements amongst the fields. Except for the two above mentioned, proportions of admitted students returned close to their original levels. Even though data fluctuated during the in-between years, it can be stated that nothing really changed remarkably as of the weights of the fields. Life returned to 'business as usual', expressing almost the same student preferences.

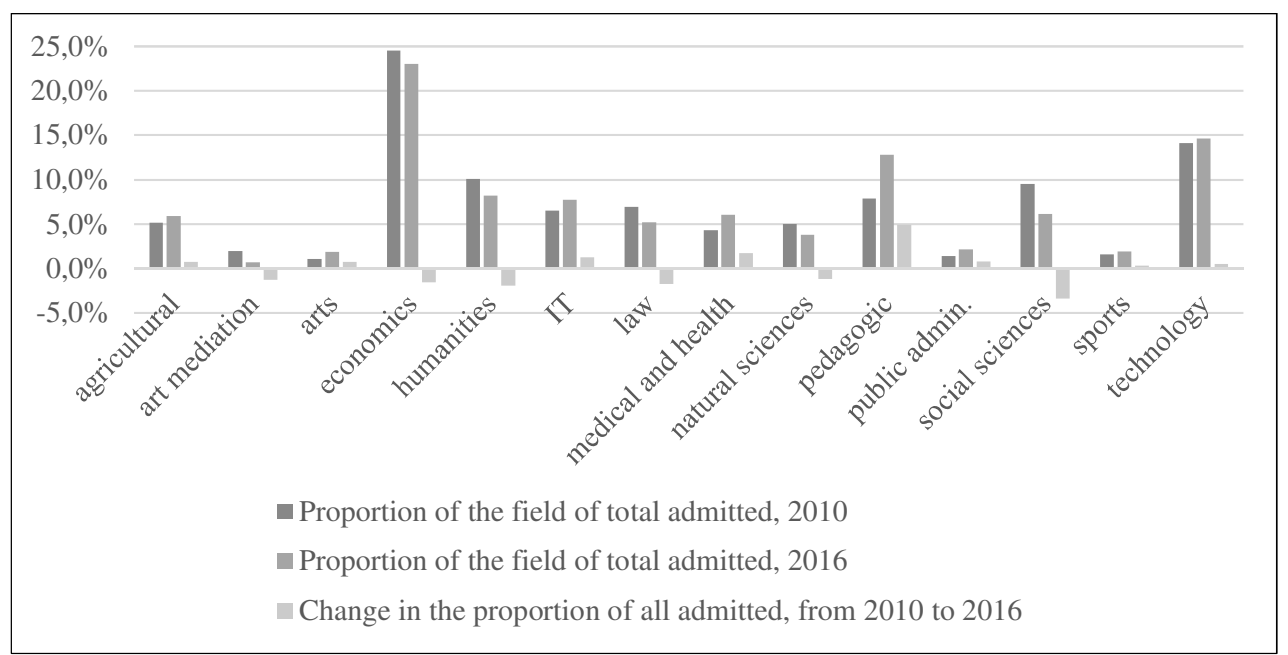

Figure 7 - Changes in the Proportions of Fields of Studies of All Admitted Students (2010-2016)

\section{Analysis of Admitted Students According to Finance Status Between 2010-2016}

All the above mentioned is even more interesting, if trends of distribution of state-funded places among fields of study are also investigated (Fig. 8).

It is apparent from Figure 8 that the number of state-funded places in economics, social sciences and law programmes suddenly fell down, and so did the number of students applying (as seen on Figure 2) and admitted into these programmes (as seen on Figure 4). This is in accordance with the pronounced aim of the policy makers to significantly cut the number of these graduates. It is also visible that the number of state-financed students is also falling at the field of technology, however, it is surely not intended by policy makers. Taking Figure 4 into account again, this decrease is in parallel with the decrease of overall admissions at the field. Fewer students become state-funded from year to year, since the number of admitted students is also going down. 


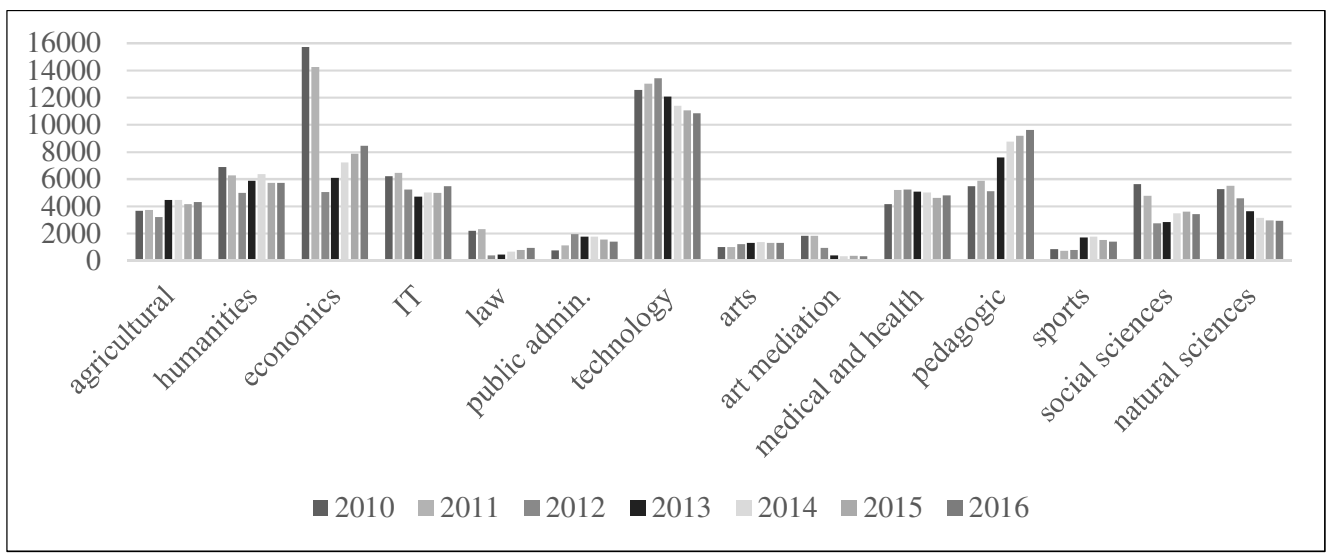

Figure 8 - State-Funded/Scholarship Admissions (2010-2016)

Fig. 9 clearly presents that two fields of study have far higher rate of fee-paying students than the others. In case of law programmes this rate is extremely high. On average, about $80 \%$ of admitted students were paying tuition fee in this time period, but in 2012 this number even reached $90 \%$. In the field of economics programmes, an average $58 \%$ of students paid tuition fee, reaching its peak in 2012 with 73\%. Meanwhile, field of economics started to regain its statefinanced places. Compared to 2010, field of economics lost almost 8,500 admitted students, mostly of state-financed ones, while in 2016 the loss in feepaying students was only less than $10 \%$ compared to that of 2010 . It can be concluded that the field of economics has been really successful as this field has been able to keep its fee-paying students.

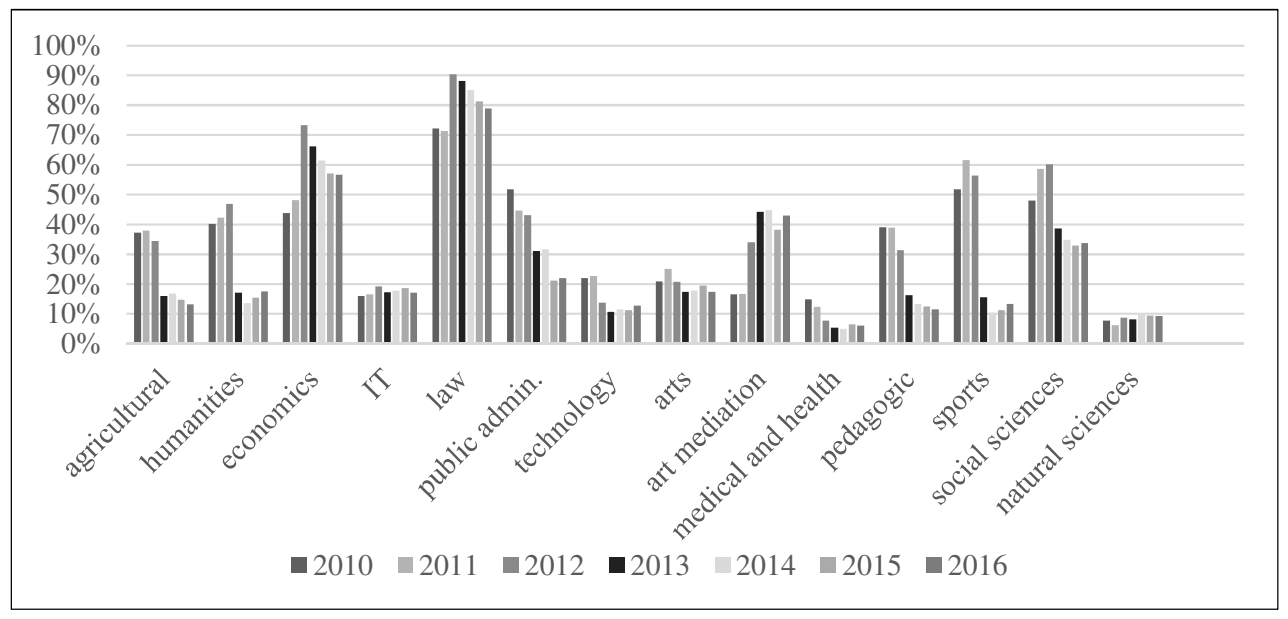

Figure 9 - The Proportion of Fee Paying Admissions in All by Fields of Study (2010-2016)

The third area where fee-paying students are far above the average is the social sciences, which is 'the silver medallist' on the list of the fields of studies losing 
the most students. Before changes in Hungarian HE started, the proportion of fee-paying students in the field of social sciences had been significantly higher. However, it has lost more than 1.5 times more of its fee-paying students than state-financed ones. Due to that trend, the proportion of state-financed students are obviously greater in this field. So this change is not the result of increasing state-financed places, it is rather about losing more fee-paying students.

\subsection{Analysis of the Distribution of Admissions by Age Group}

Besides fields of study, the age composition of admissions and its change is also worth investigating (Fig. 10).

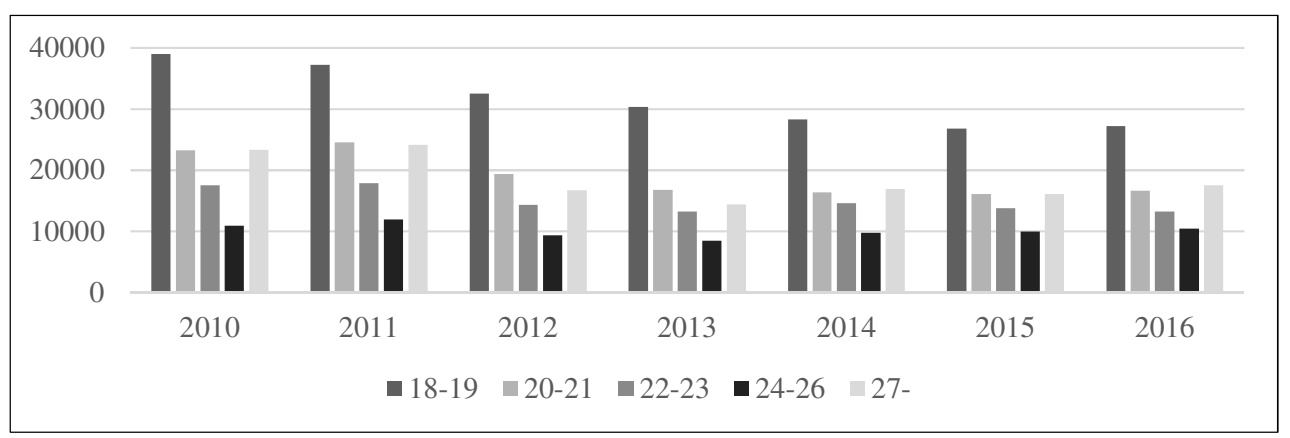

Figure 10 - Change in Admissions by Age Groups (2010-2016)

Figure 10 presents that the largest overall decrease in the number of admissions is caused by the drop in the age group freshly leaving secondary school, namely, by the 18-19 year-old applicants. Looking at 18-19 and 20-21 age groups together, the proportion of this younger generation is even higher in the decrease $(63 \%)$. The higher proportion of younger (18-21) age groups' loss of interest has had damaging effect on BSc and undivided programmes, where $92 \%$ of the lost students belong to these two age groups. Although the decrease of all students admitted to BSc/undivided programs are only $40 \%$ of the total fall, this tendency obviously has and will have an effect on the number of newly entering master level students some years later.

\subsection{Analysis of Minimum Admission Score Limits in the Time Period of 2010-2016}

Acknowledging data limitations mentioned in Chapter 2, this analysis is based on the programmes of the largest Hungarian HEIs (or on the more notable ones in terms of the specific field of study). We have examined the fields of economics, law, social sciences, technology, IT, and natural sciences programmes, and the average minimum admission scores. By analysing the data, some really unexpected and out of ordinary trends can be observed. 
In the case of economics programmes, the number of applications bottomed out including first-place applications and admissions. At the same time the number of state-financed students also hit a low. The number of these places is increasing again, however they are still far from the original level at the beginning of the time period. Meanwhile, the field could keep most of its fee-paying students. Given these circumstances, the field of economics has managed to retain its absolute winner position with the largest number of applicants and admitted students. Contrary to all of our expectations, minimum admission score limits of bachelor programmes have also risen in the case of fee-paying places. Such a phenomenon would not be surprising in the case of state-funded places, since one obviously needs to have a higher score to get into a programme with fewer statefunded places. However, the number of state-funded places has begun to increase after the bottom of 2012, admission score limits are still constantly standing high. Excellent students compete for the limited number of state-funded places. Except for the state-funded bachelor places, where the entering score limit has been standing at its rational maximum, entering score limits for fee-paying students has continued to rise, however, their number to some extent has gone down due to the increasing state financing. At master level the entering scores for feepaying and state financed education are almost equal without any significant difference. In other words, institutions have not attracted students by lowering the requirements of admission. As a result, the rise in student number at the field of economics is clearly due to students' growing interest.

In the case of BSc and undivided programmes in the field of law, there's a very similar tendency. The limited number of state-financed places results in constantly high entering score limits, however, the scores for the fee-paying students are continuously increasing. In the field of social sciences studies, the only difference is that the BSc and BA state-financed entering scores are not as high as in the case of economics and law, though, they are slightly going up as well.

An interesting phenomenon can also be observed in the field of technology programmes taking the constant decrease in student numbers into consideration. On average, admission score limits for fee-paying programmes have proved to be higher than state-funded ones in every year and on every level since 2013 in the average of the examined higher education institutions. There has been a continuous increase in the score limits for fee-paying programmes. What even more interesting is that the decrease in student numbers seems to originate from the decrease of the state-financed students, where the minimum is entering scores, especially at BSc/BA level, is also rising (While admission numbers and state -financed admissions are decreasing). The same trend can be observed in the field of IT programmes. On average, the fee-paying score limits of these programmes exceeded the state-funded ones every year on both levels from 2012 in the examined higher education institutions. The entering minimum score also shows an increasing trend since 2012 in case of state-financed students. 
The change in admission score limits of natural sciences programmes is not as expected either. This field suffered an overall decrease in the number of applications, including first-place applications and admissions. On the contrary, the entering minimum scores at both levels of education and in both financing forms have been continuously increasing.

\section{CONCLUSION}

It may be assumed that in the absence of other known relevant sociodemographic reasons the change in the habits of HE applicants has been induced by the announced state goals and trends; that is what the applicants have been reacting to. It can be assumed that student strategies responding to state and political changes have stabilised. By 2016, Hungarian HE applications and admissions have begun to settle at a certain level, showing fluctuation around a certain value.

Examining student reactions, it may be assessed that the governmental policy to promote technology, IT and natural sciences studies and constrain applications to economics, social sciences, humanities and law programmes have mostly not been effective, at least not in this timeframe. Economics programmes still continue to be the 'gold medallist' of popularity lists. There is no sign of any kind of rearrangements even starting to take shape, apart from the fact that pedagogic programmes have come slightly forward. It may be assumed that this increase has come from lost students in humanities and social sciences fields. During the examined time period six classes of students graduated from secondary school and had the opportunity to change their preferences and their chosen fields from 2011. They did not. It is also remarkable that almost a quarter of $\mathrm{HE}$ applicants are older than 27 meaning they have already established their preferences.

Hence, changes in political aspects certainly cannot be ignored, the key question is whether the quality management of a HEI is able to correctly identify student needs and expectations and whether it can effectively address those needs. Can a HEI effectively utilise state-of-the-art methods of quality management? What can they do to convince as many students as possible that it is worth entering HE, applying to a particular institution or programme even among these conditions? In a situation similar to Hungary's, this may well be the key to the survival of a higher education institution.

\section{REFERENCES}

Woodhall, M., 2007. Funding Higher Education: the Contribution of Economic Thinking to Debate and Policy Development. Washington D.C.: The World Bank. 
Dennison, J.D., 1989. Higher Education Policy In The United Kingdom Reformation or Dissolution?. The Canadian Journal of Higher Education, 19(1), pp. 87-96.

Green, D.M., 1994. What is Quality in Higher Education?. London: Society for Research into Higher Education \& Open University Press.

Felvi, 2017. Felvi - Monden, ami felsöoktatás. [online] Availabe at: $<$ www.felvi.hu> [Accessed 10 January 2017].

Központi Statisztikai Hivatal (KSH), 2017. Hungarian Central Statistical Office's website. [online] Availabe at: <www.ksh.hu> [Accessed 10 January 2017].

Nemzeti Foglalkoztatási Szolgálat (NFSZ), 2017. National Employment Service's website. [online] Availabe at: <www.nfsz.munka.hu> [Accessed 10 January 2017].

\section{ABOUT AUTHORS}

Rita Csőke is assistant professor at the Department of Management and Business Law, Eötvös Lorand University, Budapest. She works on her PhD in the field of service quality management.

Zsuzsanna Eszter Tóth is associate professor at the Department of Management and Business Law, Eötvös Lorán University, Budapest. Her research focuses on quality management and service quality issues in higher education context.

(C) 2017 by the authors. Submitted for possible open access publication under the terms and conditions of the Creative Commons Attribution (CC-BY) license (http://creativecommons.org/licenses/by/4.0/). 